\title{
Multilateral Tariff Negotiations when Production is Fixed
}

\author{
Méndez Naya, José \\ Universidade de A Coruña \\ Méndez Naya, Luciano \\ Universidade de Santiago
}

\begin{abstract}
This paper contributes to analysis of the extent to which multilateral trading agreements reached under GATT can liberalize the world economy. Its main conclusion is that free trade is not sustainable if production is fixed exogenously and utility is non-transferable. If production is fixed and utility is transferable, free trade is possible but is not necessary for maximization of welfare.
\end{abstract}

- JEL Classifications: F12, F13, F15

- Key Words: International Trade, Trade Negotiations, Imperfect Competition

\section{Introduction}

According to the established theory of international trade, free trade is in general of benefit to all trading countries. The fact is, however, that the flow of international trade had for centuries been impeded by trade barriers of one kind or another. This paper adds to existing literature a new partial justification of them.

Since World War II multilateral tariff negotiations have taken place in the framework of the General Agreement on tariffs and Trade (GATT). GATT established a set of rules for the conduct of international trade, notably the "most favoured nation" (MFN) principle. GATT signatories treat all other signatories as MFNs, except that Article 24 allows for the establishment of regional customs

*Corresponding address: Méndez Naya, José, Facultade de Ciencias Económicas y Empresariales. Campus de Elvñ a s/n (15071) A Coruñ a Spain. Tel.: 981-167050. Fax: 981-167070. E-mail: jmn@udc.es (C2002-Center for International Economics, Sejong Institution, All Rights Reserved. 
unions and free-trade areas whose members may trade with each other under more liberal conditions than those afforded to GATT nations in general. While pursuing general liberalization (multilateralism), GATT thus also allows for faster regional liberalization (regionalism). This paper discusses both general and regional liberalization with respect to trade in goods for which production by each country is essentially fixed (a premise we discuss below).

It has traditionally been believed that although large countries can momentarily use tariffs to their advantage, in the long run tariff wars leave all countries worse off. Using a model of imperfect competition, Gros (1987) estimated that a tariff. war between two countries of equal size causes a welfare loss equivalent to a drop in income of about 4 percent. However, it was pointed out long ago by Johnson (1953) that when different countries have different elasticities of demand and supply, one may benefit from a tariff war. This finding naturally constitutes an important justification of trade barriers.

Johnson's paper spurred the investigation of more complicated models including other variables that might lead to similar conclusions (see, for instance, Otani (1980), Thrusby and Jensen (1983), Mayer (1981), Riezman (1982) and Kenan and Riezman (1988). For example, Mayer (1981) and Kenan and Riezman (1988) emphasized that a country will prefer a tariff war to free trade with a smaller trading partner. Park (2000) studied how changes in the structure of trade agreements affect the outcome of negotiations between countries of different sizes. Chang (1991) noted the importance of the extent to which countries depend on trade: the more dependent on trade a country is, the more likely it is to lose in a tariff bargaining game. Under imperfect competition tariffs may also be induced by external factors such as the exploitation of international market power (Brander and Spencer 1985). For surveys on trade policy under imperfect competition, see Helpman and Krugman (1989) and Harris (1989).

In this paper we examine a three-country model of imperfect competition in international trade. It is proved that if firms' output is given exogenously, and in the absence of mechanisms of utility exchange, there will always be a country that is better off under the conditions of the noncooperative tariff equilibrium than under free trade. In other words, we supplement the results of existing literature by showing that under these conditions, too, free trade is not sustainable.

The hypothesis that firms' output is fixed is of course valid in the short term. It would also appear to be applicable in certain real contexts even in the long term. Specifically, it would be applicable when the volume of production is to a large 
extent determined by factors beyond producers' control, as in agriculture and fishing. Applicability to agriculture is particularly interesting because, as is well known, agriculture has been the biggest obstacle in GATT negotiations, EU resistance to reform of its Common Agricultural Policy having prevented agreement at Seattle and almost prevented agreement in the earlier Uruguay Round.

If production is fixed exogenously, the only decision producers have to take is to determine the distribution of their production among the available national markets. Since the amount of production assigned to each market depends on those of the others, the whole market is effectively integrated; see Markusen (1981), Markusen and Venables (1988) and Venables (1990, 1994). Since world markets are undoubtedly becoming increasingly integrated, our model is realistic in this regard.

In this integrated context, countries' commercial policies are interdependent (which is one of the most important reasons for multilateral tariff negotiations). When we talk about strategic trade policies, the term 'strategic' is therefore used in the same way as in game theory. In establishing their policies, agents are conscious of their mutual interaction and behave strategically in the sense that, when deciding which course of action to take, they consider the possible effects on the other agents and the fact that the latter are expected to behave in the same way.

In our model, as in Brander (1981) and Brander and Krugman (1983), strategic interaction among oligopolistic producers gives rise to reciprocal dumping. Each firm dumps into other firms' home markets, and the resulting international price differences cause two-way trade even in identical products. The model thus combines international trade and industrial organization, and its analysis throws up several novel features in each area, because oligopolistic interactions among private producers turn out to be capable of significantly altering the way in which commercial policies interact. See Dixit (1984) for a selective review of the literature on imperfectly competitive international trade.

Section II of this paper presents the basic model used. In Section III the effects of alternative commercial policies on countries' tariffs and welfare are analysed. The influence of firms' sizes and the transferability on commercial policy is investigated in Section IV, and Section V concludes.

\section{The Model}

Let us consider three countries denoted 1, 2 and 3, one firm in each of which 
produces a certain good that is homogeneous with those produced by the corresponding firms of the other countries. The total production of country $i$ 's firm (hereinafter called that firm's size) is $e i$, and the quantities sold in country $i$ by the firms of countries 1, 2 and 3 are $x i, y_{i}$ and $z i$, respectively.

Demands are derived from a strictly concave aggregate utility function, and afford the following expressions for $p_{1}, p_{2}$ and $p_{3}$, the market prices in countries 1 , 2 and 3, respectively:

$$
\begin{aligned}
& p_{1}=a-b\left[e_{1}-\left(x_{2}+x_{3}\right)+y_{1}+z_{1}\right] \\
& p_{2}=a-b\left[e_{2}-\left(y_{1}+y_{3}\right)+x_{2}+z_{2}\right] \\
& p_{3}=a-b\left[e_{3}-\left(z_{2}+z_{1}\right)+y_{3}+x_{3}\right]
\end{aligned}
$$

The profits $\pi_{1}, \pi_{2}$ and $\pi_{3}$ of the firms of countries 1,2 and 3 are

$$
\begin{aligned}
& \pi_{1}=p_{1}\left[e_{1}-\left(x_{2}+x_{3}\right)+\left(p_{2}-t_{2}\right) x_{2}+\left(p_{3}-t_{3}\right) x_{3}\right] \\
& \pi_{2}=p_{2}\left[e_{2}-\left(y_{1}+x_{3}\right)+\left(p_{1}-t_{1}\right) y_{1}+\left(p_{3}-t_{3}\right) y_{3}\right] \\
& \pi_{3}=p_{3}\left[e_{3}-\left(z_{3}+z_{1}\right)+\left(p_{2}-t_{2}\right) z_{2}+\left(p_{1}-t_{1}\right) z_{1}\right]
\end{aligned}
$$

where $t_{1}, t_{2}$ and $t_{3}$ are the tariffs imposed by countries 1,2 and 3, respectively, on their imports. Note that no country discriminates between the others by making the tariff depend on the origin of the goods, i.e. all the countries treat each other as GATT signatories in this respect. Production costs are not included in the model because they are considered to have been incurred previously and so are sunk costs.

Each country's welfare includes consumer surplus, tariff income and firms' profits. Therefore, assuming that consumer utility can be represented by a simple quadratic function, the welfare $w_{1}$ of country 1 is given by

$$
w_{1}=a q_{1}-1 / 2 b q_{1}^{2}-p_{1} q_{1}+t_{1} y_{1}+t_{1} z_{1}+\pi_{1}
$$

with analogous expressions for those of countries 2 and 3.

Trade policy is modelled as a two-stage game in which all governments simultaneously set tariffs in the first stage, leaving the countries' firms to compete as Cournot oligopolists in the second stage. The game is solved for its sub-game perfect equilibrium by backward induction. 


\section{Effects of Bilateral and Multilateral Cooperation on Tariffs and Welfare}

Cournot competition leads to the following equilibrium quantities for country 1's firm:

$$
\begin{gathered}
x_{2}=\left(2 b e_{1}-2 t_{2}-t_{1}+t_{3}\right) /(6 b) \\
x_{3}=\left(2 b e_{1}-2 t_{3}-t_{1}+t_{2}\right) /(6 b) \\
e_{1}-\left(x_{2}+x_{3}\right)=\left(2 b e_{1}+2 t_{1}+t_{2}+t_{3}\right) /(6 b)
\end{gathered}
$$

Together with analogous expressions for the other firms, eqs. 4 imply that country 1's market equilibrium is given by

$$
\begin{gathered}
p_{1}=\left[6 a-2 b\left(e_{1}+e_{2}+e_{3}\right)+2 t_{1}-t_{2}-t_{3}\right] / 6 \\
q_{1}=\left[2 b\left(e_{1}+e_{2}+e_{3}\right)+2 t_{1}+t_{2}+t_{3}\right] /(6 b)
\end{gathered}
$$

Thus tariffs and the firms' sizes influence equilibrium prices and quantities as intuition suggests: the quantity sold in country 1 increases with the firms' sizes and with the other two countries' tariffs, and decreases as country 1's tariff increases, while the equilibrium price behaves in a precisely opposite way. Mutatis mutandis, the analysis for countries 2 and 3 is the same.

\section{A. Non-cooperation}

In the non-cooperative situation each country employs its tariff $t_{i N}$ to maximize its welfare, $w_{i N}$. The quantities and prices given by eqs. 4 and 5 (and the analogous expressions for countries 2 and 3) imply that at equilibrium

$$
\begin{gathered}
t_{1 N}=(b / 18)\left(5 e_{2}+5 e_{3}-e_{1}\right) \\
w_{1 N}=a e_{1}+(b / 648)\left(118 e_{2} e_{3}-164 e_{1} e_{2}-164 e_{1} e_{3}-268 e_{1}^{2}+77 e_{2}^{2}+77 e_{3}^{2}\right)
\end{gathered}
$$

with analogous expressions for countries 2 and 3. Note that equilibrium tariffs depend on the three firms' sizes as intuition suggests: the larger a country's firm is, the less protection it needs and therefore the lower the country's tariff is. 


\section{B. Cooperation}

There are two cooperative situations: either all three countries cooperate (multilateralism), or two of them form a customs union from which the third is excluded (regionalism).

\section{B1. Multilateral Cooperation}

In the multilateral case the three countries set their tariffs to maximize the sum of their individual utility functions, $w_{G}=w_{1}+w_{2}+w_{3}$. Solution of the trade policy game in these conditions shows that

$$
t_{1 G}=t_{3 G}=t_{3 G}
$$

and that

$$
w_{G}=a\left(e_{1}+e_{2}+e_{3}\right)-(b / 6)\left(e_{1}^{1}+e_{2}^{2}+e_{3}^{2}+2 e_{1} e_{2}+2 e_{1} e_{3}+2 e_{2} e_{3}\right)
$$

regardless of the actual value of the common tariff, which is therefore indeterminate.

This result raises the question of what criteria might be used in this situation to set the tariff. One possible criterion might be to favour redistribution of income from consumers to producers by setting a high tariff. If tariffs are prohibitive, firms will not sell their product abroad and the result will be a monopolistic market in every country. This would be the most profitable market structure for firms and the most harmful for consumers, who would benefit most from free trade. GATT tariff negotiations could be interpreted from this point of view.

\section{B2. Bilateral Cooperation}

To analyse this case we suppose that countries 1 and 2 decide to cooperate with each other and to act non-cooperatively with respect to country 3. Countries 1 and 2 accordingly set their joint tariff $t_{B}$ to maximize

$$
w_{B}=w_{1}+w_{2}
$$

We find that 


$$
\begin{aligned}
& t_{B}=(b / 5)\left(9 / 2 e_{3}-e_{1}-e_{2}\right) \\
& t_{3 B}=(b / 5)\left(e_{1}+e_{2}+1 /{ }_{2} e_{3}\right)
\end{aligned}
$$

where $t_{3 B}$ is the tariff set by country 3 , and that the corresponding welfare levels $w_{B}$ and $w_{3 B}$ are given by

$$
\begin{gathered}
w_{B}=a\left(e_{1}+e_{2}\right)-(b / 150)\left[36\left(e_{1}^{2}+e_{2}^{2}\right)-56 e_{3}^{2}+72 e_{1} e_{2}+31 e_{1} e_{3}+31 e_{2} e_{3}\right] \\
w_{3 B}=a e_{3}+(b / 150)\left[9\left(e_{1}^{2}+e_{2}^{2}\right)+89 e_{3}^{2}+18 e_{1} e_{2}-11 e_{1} e_{3}-11 e_{2} e_{3}\right]
\end{gathered}
$$

In fact, the assumption that the cooperating countries set the same tariff is not necessary; the tariffs and welfare levels of eqs. 11 and 12 follow simply from maximization of $w_{B}$ by countries 1 and 2 and of $w_{3 B}$ by country 3 .

\section{Influence of the Firms' sizes and the Transferability of Utility on Cooperativeness}

In this section we compare tariffs and welfare levels in the non-cooperative, bilaterally cooperative and multilaterally cooperative situations in relation to the size of the firms and the transferability of utility.

Proposition 1. a) The smaller a country's firm is, the higher its non-cooperative tariff.

b) Bilateral cooperation may increase all tariffs with respect to their non-cooperative values. The larger the third country's firm is relative to those of the cooperating countries, the more likely is this result.

c) Under multilateral cooperation tariffs may be higher or lower than under bilateral cooperation or non-cooperation without affecting national welfare.

Proof. a) By eq. 6 .

b) By eqs. 6 and 11,

$$
\begin{aligned}
& t_{B}-t_{1 N}=(b / 90)\left(56 e_{3}-13 e_{1}-43 e_{2}\right) \\
& t_{3 B}-t_{3 N}=(b / 90)\left(14 e_{3}-7 e_{1}-7 e_{2}\right)
\end{aligned}
$$

c) As we saw in Section III.II.I, under multilateral cooperation tariffs are indeterminate.

Proposition $2^{\circ}$ If utility is transferable, then

a) multilateral cooperation is always advantageous, and its advantage over non-cooperation increases with the disparity among the firms' sizes; 
b) bilateral cooperation is always advantageous to the cooperating countries and disadvantageous to the third;

c) under bilateral cooperation, cooperating countries gain more, and the third country loses more, the greater the absolute difference $d$ between the third firm's size and the mean of those of the cooperating firms;

d) for a fixed value of $d$, bilateral cooperation is more profitable for the cooperating firms' countries, and more detrimental to the third country, the greater the absolute size difference $d$ between the cooperating firms; and

e) for a fixed absolute size difference D between the largest and smallest firms, bilateral cooperation between the two smallest or the two largest is more profitable for the cooperating firms' countries, and more detrimental to the third country, the less the absolute difference $\mathrm{d}$ between the cooperating firms' sizes.

Proof. Elementary calculations show that

$$
w_{G}-\left(w_{1 N}+w_{2 N}+w_{3 N}\right)=(b / 72) \operatorname{Var}\left(e_{1}, e_{2}, e_{3}\right)
$$

(for the definition of Var see the footnote ${ }^{1}$ ); that

$$
\begin{gathered}
w_{B}-\left(w_{1 N}+w_{2 N}\right)=(b / 5400)\left\{1099 \operatorname{Var}\left(e_{1}, e_{2}, e_{3}\right)-874 \operatorname{Var}\left(e_{1}, e_{2}\right)\right\} \\
=(b / 5400)\left(255 \operatorname{Var}\left(e_{1}, e_{2}\right)+(2198 / 3) d^{2}\right) \\
w_{3 B}-w_{3 N}=(b / 2700)\left\{653 \operatorname{Var}\left(e_{1}, e_{2}\right)-728 \operatorname{Var}\left(e_{1}, e_{2}, e_{3}\right)\right\} \\
=(-b / 2700)\left\{75\left(e_{1}, e_{2}\right)+(1456 / 3) d^{2}\right\}
\end{gathered}
$$

that in case $e$

$$
\begin{gathered}
w_{B}-\left(w_{1 N}+w_{2 N}\right)=(b / 16200)\left\{887 d^{2}+2198 D(D-d)\right\} \\
w_{3 B}-w_{3 N}=(-b / 16200)\left\{953 d^{2}+2912 D(D-d)\right\}
\end{gathered}
$$

and that when the smallest and largest firms collaborate

$$
\begin{gathered}
w_{B}-\left(w_{1 N}+w_{2 N}\right)=(b / 16200)\left\{887 d^{2}-2198 P\right\} \\
w_{3 B}-w_{3 N}=(-b / 16200)\left\{953 d^{2}-2912 P\right\}
\end{gathered}
$$

where $P$ is the product of the absolute size differences between the cooperating firms and the third firm.

Part a follows from eq. 14; Parts $b$ and d from eqs. 15 and 16; and Part e from eqs. 17 and 18. Part $c$ follows from eqs. 15 and 16 when the two smallest or two largest firms collaborate, and from eqs.

The variance $\operatorname{Var}\left(s_{1}, \ldots, s_{n}\right)$ of $n$ real numbers $s_{1}, \ldots, s_{n}$ with mean $m$ is defined by $\operatorname{Var}\left(s_{1}, \ldots\right.$, $\left.s_{n}\right)=\sum_{i=1}^{n}\left(s_{i}-m\right)^{2}$ 
19 and 20 when the smallest and largest firms collaborate (in which case the absolute value of $d$ decreases with increasing $P$ ).

In what follows we assume that utility is non-transferable. In this situation, even if countries cooperate by setting their tariffs to maximize their joint utility function, the welfare achieved by each is given by its own individual utility function. We now analyse the incentives countries have to cooperate in this situation.

Proposition $3^{*}$ (The non-sustainability of free trade) If the three firms are of equal size, no country gains more from free trade than from non-cooperative competition; if not, the country with the smallest firm is adversely affected by free trade.

Proof. Let $w_{i G}(t)(i=1,2,3)$ denote country i's welfare when joint welfare is maximized by adoption of a common tariff $t$. The three countries' gains from free trade with respect to non-cooperation are

$$
\begin{gathered}
w_{1 G}(t)-w_{1 N}=(b / 648)\left[88 e_{1}^{2}-41\left(e_{2}^{2}+e_{3}^{2}\right)+20 e_{1} e_{2}+20 e_{1} e_{3}-46 e_{2} e_{3}\right]+ \\
(2 t / 3)\left[\frac{1}{2}\left(e_{2}+e_{3}\right)-e_{1}\right] \\
w_{2 G}(t)-w_{2 N}=(b / 648)\left[88 e_{2}^{2}-41\left(e_{1}^{2}+e_{3}^{2}\right)+20 e_{1} e_{2}+20 e_{2} e_{3}-46 e_{1} e_{3}\right]+ \\
(2 t / 3)\left[1 / 2\left(e_{1}+e_{3}\right)-e_{2}\right] \\
w_{3 G}(t)-w_{3 N}=(b / 648)\left[88 e_{3}^{2}-41\left(e_{1}^{2}+e_{2}^{2}\right)+20 e_{1} e_{3}+20 e_{2} e_{3}-46 e_{1} e_{2}\right]+ \\
(2 t / 3)\left[1 / 2\left(e_{1}+e_{2}\right)-e_{3}\right]
\end{gathered}
$$

If $e_{1}=e_{2}=e_{3}$, there are no gains from cooperation whatever the common tariff. To prove the second part of the Proposition we re-write the first of eqs. 21 for $t=0$ as

$$
\begin{gathered}
w_{1 G}(0)-w_{1 N}=(b / 648)\left\{\left(88 e_{1}^{2}-41 e_{2}^{2}-41 e_{3}^{2}\right)+\left(20 e_{1} e_{2}-20 e_{3} e_{2}\right)+\right. \\
\left.\left(20 e_{1} e_{3}-20 e_{2} e_{3}\right)-6 e_{2} e_{3}\right\}
\end{gathered}
$$

Assuming without loss of generality that firm 1 is the smallest, then and $\left(88 e_{1}^{2}-41 e_{2}^{2}-41 e_{3}^{2}<\right.$ $\left.6 e_{1}^{2}<6 e_{2} e_{3}\right)$ and $\left(20 e_{1} e_{3}-20 e_{2} e_{3}\right)$ are both negative, so that

$$
w_{1 G}(0)-w_{1 N}<0
$$

Proposition $4^{*}$ (Size dependence of the advantages of multilateral cooperation). The greater the common tariff imposed when all three countries cooperate, the greater are the gains of the smallest firm's country with respect to non-cooperation, if any, and the smaller are the gains of the largest firm's country, if any.

Proof. Assuming without loss of generality that firm 1 is the smallest and firm 3 the largest, the Proposition follows from eqs. 21

What we have not yet shown is whether there is any common tariff that is more beneficial than non- 
cooperation for all three countries. The following proposition clarifies this.

Proposition $5^{\circ}$ (The desirability of multilateral cooperation) Only if the two smallest or the two largest firms differ little in size in comparison with their differences from the third are there common tariffs that for all three countries are more beneficial than non-cooperation.

Proof. We assume without loss of generality that $e_{1} \leq e_{2} \leq e_{3}$ and that $b=1$ (this simply amounts to taking $b$ as the unit of the tariff $t$ ), and we note that

$$
w_{i G}(t)-w_{i N}=(1 / 648)\left(88 x^{2}-41 y^{2}-41 z^{2}+20 x y+20 x z-46 y z\right)
$$

where $x=e_{1}-2 t, y=e_{1}-2 t$ and $z=e_{3}-2 t$. We write $\Delta_{i}(x, y, z)$ for the right-hand side of eq. 24 . Our objective is to determine those regions of $(x, y, z)$ space in which $\Delta_{i}>0$ for all $i$. We begin by observing that, by arguments analogous to that of Proposition $4, \Delta_{1}$ can only be positive if $x<0$ and $\Delta_{3}$ can only be positive if $z>0$; hereinafter we denote by $U$ the region of positive $z$ and negative $x$. We then find the surfaces for which $\Delta_{i}=0$; the parts of these surfaces that lie near the origin in $U$ are shown in Figures 1, 2 and 3 for $i=1,2$ and 3, respectively. Calculation of the signs of the $\Delta_{i}$ on the $y$ axis, the positive $z$ axis and the negative $x$ axis show that, in $U, \Delta_{1}>0$ below the surface shown in Figure 1 (i.e. on the same side as the negative $z$ axis), $\Delta_{2}>0$ in those regions defined by the surface of Figure 2 that contain the $y$ axis, and $\Delta_{3}>0$ above the surface of Figure 3 (i.e. on the same side as the positive $z$ axis). All three conditions are satisfied simultaneously only in the two 'triangular' regions shown in Figure 4. Inspection of these regions shows that in the one on the right (i.e. with $y$ negative), the values of $x$ and $y$ differ little in comparison with their differences from that of $z$, which is positive; while in the one on the left (with $y$ positive), the values of $y$ and $z$ differ little in comparison with that of $x$, which is negative.

It may be noted that the quasi-conical form of the beneficial regions shown in Figure 4 suggests that, at least within certain bounds, the range of tariff values that are beneficial to all three countries increases with the difference in size between the similar firms and the third, likewise increases with the mean size of the firms, and is unaffected if the sizes of all three firms are increased by the same amount.

\section{Figure 1}

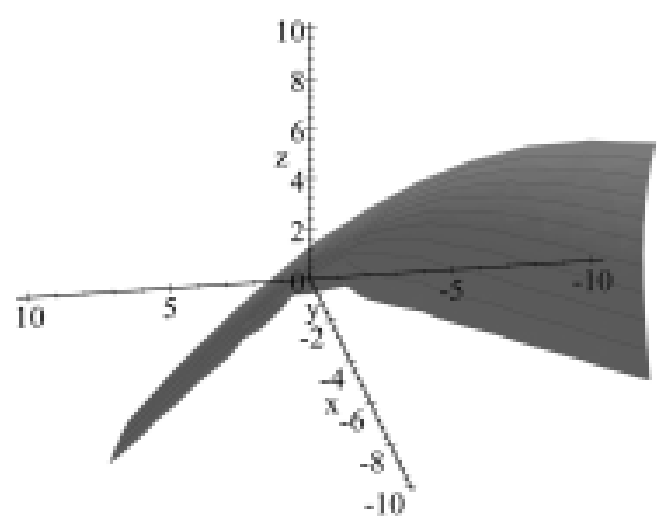


Figure 2

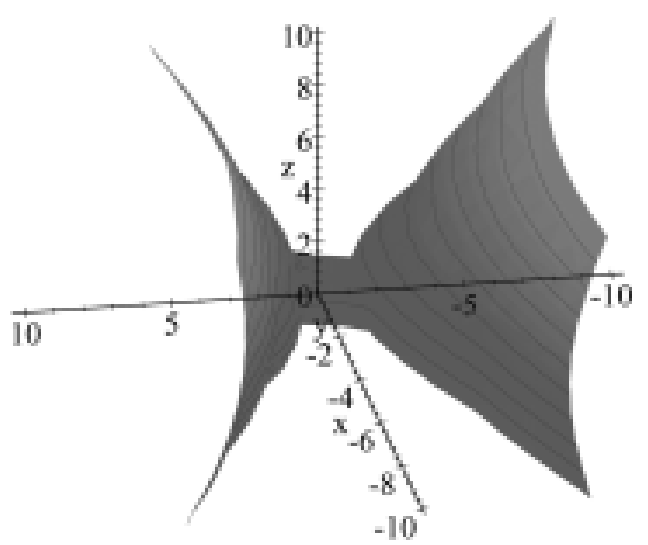

Figure 3

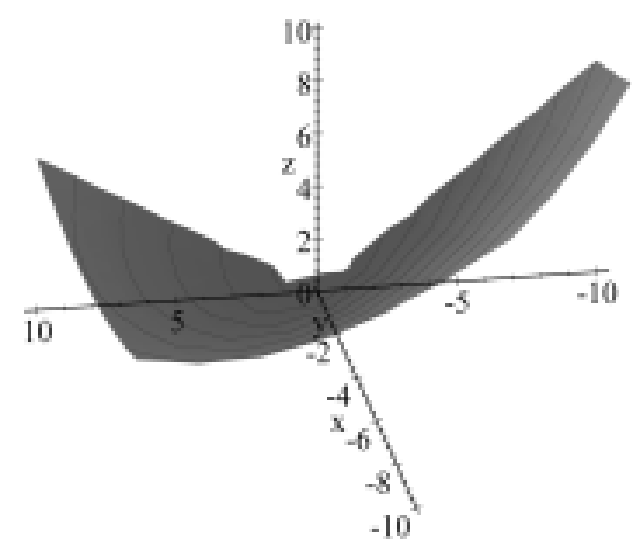

Figure 4

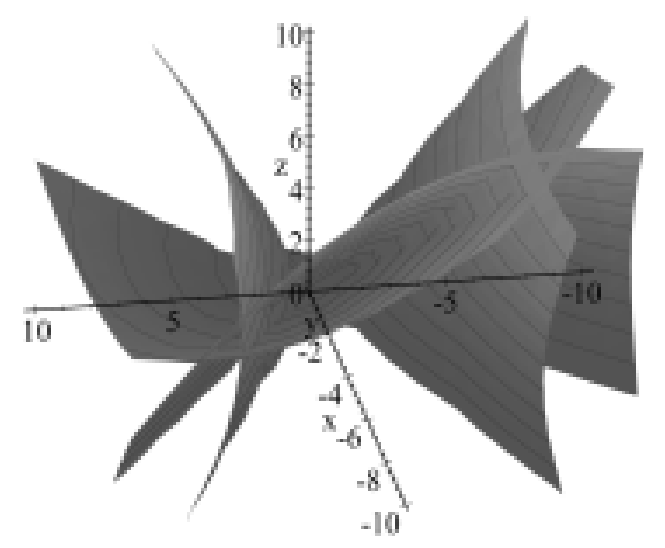


Finally, we consider the viability of bilateral cooperation when utility is nontransferable. We use the following notation: $w_{i B}$ is the welfare of country $i$ under bilateral cooperation, $\Delta_{i}=w_{i B}-w_{i N}, \beta=\mathrm{b} / 16200, x=e_{1}-e_{3}, y=e_{2}-e_{3}, d_{12}=e_{1}-$ $e_{2}, d_{123}=12_{2}\left(e_{1}+e_{2}\right)-e_{3}$, and $r=\left(e_{l}-e_{m}\right) /\left(e_{m}-e_{s}\right)$, where $e_{l}, e_{m}$ and $e_{s}$ are the sizes of the largest, middle-sized and smallest firms, respectively.

Proposition 6. If utility is non-transferable,

a) bilateral cooperation between the countries with the two smallest or two largest firms is advantageous to them if $0.77<y / x<1.29$;

b) bilateral cooperation between the countries with the smallest and largest firms is advantageous to them if $1.17<y / x<0.85$

c) if cooperation between the countries with the smallest and largest firms is advantageous to them, then for fixed $\delta_{123}$ the advantage of cooperation increases for both with the absolute difference between their firms' sizes;

d) if cooperation between the countries with the two smallest or two largest firms is advantageous to them, then for fixed $d_{12}$ the advantage of cooperation increases for both with the absolute difference between the mean of their firms' sizes and the size of the third firm; and

e) i) the countries with the two largest firms have reason to cooperate if $r<0.296$; ii) the countries with the largest and smallest firms have reason to cooperate if $0.853<r<1.172$; and iii) the countries with the two smallest firms have reason to cooperate if $r>3.377$.

Proof. We find that

$$
\begin{gathered}
\Delta_{1}=\beta\left(2596 e_{2}^{2}-1709 e_{2}^{2}+1099 e_{3}^{2}+212 e_{1} e_{2}-5404 e_{1} e_{3}+3206 e_{2} e_{3}\right)= \\
b\left\{(1099 / 3600) V_{3}-(437 / 2700) V_{2}+(287 / 2160)\left[e_{1}\left(e_{1}-2 e_{3}\right)+e_{2}\left(2 e_{3}-e_{2}\right)\right]\right\}
\end{gathered}
$$

and that

$$
\begin{gathered}
\Delta_{2}=\beta\left(2596 e_{2}^{2}-1709 e_{1}^{2}+1099 e_{3}^{2}+212 e_{1} e_{2}-5404 e_{2} e_{3}+3206 e_{1} e_{3}\right)= \\
b\left\{(1099 / 3600) V_{3}-(437 / 2700) V_{2}+(287 / 2160)\left[e_{2}\left(e_{2}-2 e_{3}\right)+e_{1}\left(2 e_{3}-e_{1}\right)\right]\right\}
\end{gathered}
$$

where $V_{2}=\operatorname{Var}\left(e_{1}, e_{2}\right)$ and $V_{3}=\operatorname{Var}\left(e_{1}, e_{2}, e_{3}\right)$. Noting that variances are invariant under translation and that similarly, for all $k$,

$e_{1}\left(e_{1}-2 e_{3}\right)+e_{2}\left(2 e_{3}-e_{2}\right)=\left(e_{1}+k\right)\left[\left(e_{1}+k\right)-2\left(e_{3}+k\right)\right]+\left(e_{2}+k\right)\left[2\left(e_{3}+k\right)-\left(e_{2}+k\right)\right]$

we see that the effects of bilateral cooperation are unaltered by increasing or decreasing all firms' sizes by the same quantity. In what follows we accordingly work with $x=e_{1}-e_{3}, y=e_{2}-e_{3}$ and $z=e_{3}-$ $e_{3}=0$, and write eqs. 25 and 26 as

$$
\begin{aligned}
& \Delta_{1}=\beta\left(2596 x^{2}-1709 y^{2}+212 x y\right) \\
& \Delta_{2}=\beta\left(2596 y^{2}-1709 x^{2}+212 x y\right)
\end{aligned}
$$


These equations imply that $\Delta_{1}>0$ if $1.172<y / x<1.296 \mathrm{x}$ and that $\Delta_{2}>0$ if $y / x<0.853$ or $y / x>0.772$. The regions of the $(x, y)$ plane in which both conditions are fulfilled are shown unshaded in Figure 5 together with the order of the firms' sizes in each. This proves Parts a and $b$ of the Proposition. Note that in all the unshaded regions of Figure 5 the absolute values of $x$ and $y$ are quite similar. We now re-write eqs. 27 and 28 in the form

$$
\begin{gathered}
\Delta_{1}=(\beta / 4)\left[675(x-y)^{2}+8610(x-y)(x+y)+1099(x+y)^{2}\right]= \\
(\beta / 4)\left[675 d_{12}^{1}+17220 d_{12} d_{123}+4396 d_{123}^{2}\right] \\
\Delta_{2}=(\beta / 4)\left[675(x-y)^{2}+8610(x-y)(x+y)+1099(x+y)^{2}\right]= \\
(\beta / 4)\left[675 d_{12}^{2}+17220 d_{12} d_{123}+4396 d_{123}^{2}\right]
\end{gathered}
$$

whence

$$
\begin{gathered}
\partial \Delta_{1} / \partial d_{12}=5 \beta(498 x+363 y) \\
\partial \Delta_{2} / \partial d_{12}=-5 \beta(363 x+498 y)
\end{gathered}
$$

Part $c$ now follows by examination of the signs of $\partial \Delta_{1} / \partial d_{12}$ and $\partial \Delta_{2} / \partial d_{12}$ in each of the unshaded regions of Figure 5, taking into account the dependence of the absolute value of $d_{12}$ on the sign of the latter. Part $\mathrm{d}$ follows from a similar analysis of

$$
\begin{aligned}
& \partial \Delta_{2} / \partial d_{12}=-5 \beta(363 x+498 y) \\
& \partial \Delta_{2} / \partial d_{123}=14 \beta(363 y+229 x)
\end{aligned}
$$

Finally, Part e is obtained by noting that $r=y /(x-y)$ when $e_{1}<e_{2}<e_{3}, r=x /(x-y)$ when $e_{2}<e_{1}<$

\section{Figure 5}

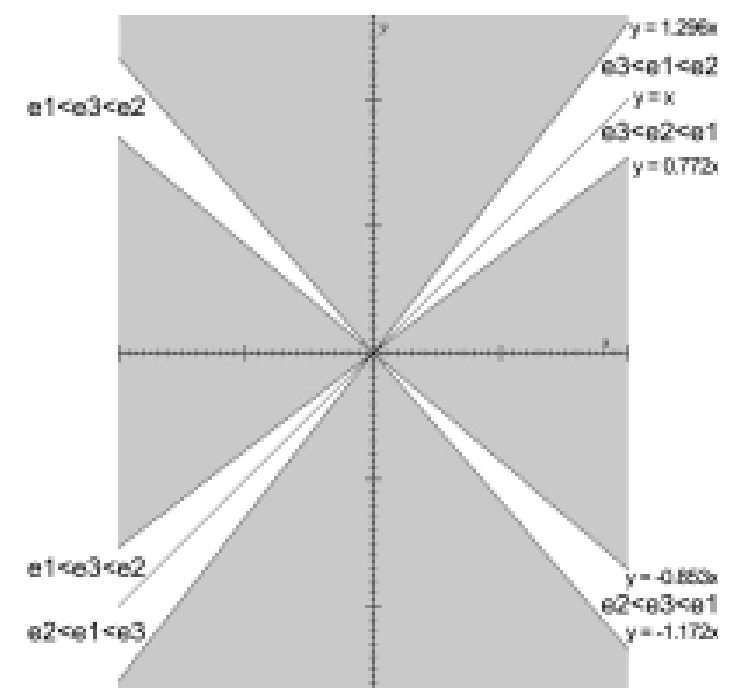


$e_{3}, r=-y / x$ when $e_{1}<e_{3}<e_{2}, r=-x / y$ when $e_{2}<e_{3}<e_{1}, r=(y-x) / x$ when $e_{3}<e_{1}<e_{2}$ and $r=(x-$ $y) / y$ when $e_{3}<e_{2}<e_{1}$; and by then considering the behaviour of these functions in the corresponding regions of Figure 5 .

\section{Concluding Remarks}

Assuming exogenous determination of production, this paper adds to the existing literature a new justification of trade barriers, and analyses the effects of firms' sizes and the transferability of utility on the advantages of multilateral or bilateral cooperation among countries. In accordance with previous literature, it finds that free trade is not sustainable if utility is not transferable.

However, three results differ from those of previous literature dealing with this situation:

1) if the countries are symmetric, none gains more from free trade than from a tariff war;

2 ) if the countries are not symmetric, there is one that always prefers noncooperation to free trade, regardless of the degree of asymmetry; and

3 ) this firm is the smallest (whereas traditional theory states that it is large countries that benefit from a tariff war).

\section{Acknowledgement}

Xunta de Galicia for financial support through projects PGIDT99PXI10004A and XUGA20103A97

Received 6 December 2000, Accepted 29 November 2001

\section{References}

Brander, J. A. (1981), "Intra-industry Trade in Identical Commodities", Journal of International Economics, 11, 1-14.

Brander, J. A. and P. R. Krugman (1983), "A Reciprocal Dumping Model of International Trade", Journal of International Economics, 15, 313-321.

Brander, J. A. and B. Spencer (1985), "Export Subsidies and International Market Share Rivalry", Journal of International Economics, 18, 83-100.

Chang, K. S. (1991), "Bilateral Trade Negotiations and Trade Diversification: Evidence from Semi-Industrialized Countries", Journal of Development Economics, 18, 83-100.

Dixit, A. K. (1984), "International Trade Policy for Oligopolistic Industries", Economic 
Journal, suppl., 1-16.

Gros, D. (1987), "A Note on the Optimal tariff, Retaliation and the Welfare Loss from tariff Wars in a Framework With Intra-Industry Trade", Journal of International Economics, 23, 357-367.

Harris, R. G. (1989), "The New Protectionism Revisited", Canadian Journal of Economics, 22, 751-78.

Helpman, E. and P. Krugman (1989), Ttrade Policy and Market Structure. Cambridge, MIT Press.

Johnson, H.G. (1953), “Optimal tariffs and Retaliation”, Review of Economic Studies, 21, 142-53.

Kenan, J. and R. Riezman (1988), "Do Big Countries Win tariff Wars", International Economic Review, 29, 81-85.

Markusen, J. R. (1981), "Trade and the Gains from Trade with Imperfect Competition", Journal of International Economics, 11, 531-551.

Markusen, J. R. and A.J. Venables (1988), "Trade Policy with Increasing Returns and Imperfect Competition: Contradictory Results from Competing Assumptions", Journal of International Economics 24,347-350.

Mayer, W. (1981) "Theoretical Considerations on Negotiated tariff Adjustments", Oxford Economic Papers, 33, 135-53.

Otani, Y. (1980), "Strategic Equilibrium of tariffs and General Equilibrium", Econometrica, 48, 643-662.

Park, J. H. (2000), "International Trade Agreements Between Countries of Asymmetric Size", Journal of International Economics, 50, 473-95.

Riezman, R. (1982), “Tariff Retaliation from a Strategic Viewpoint”, Southern Economic Journal, 48, 583-93.

Thursby, M. and R. Jensen (1983), "A Conjectural Variation Approach to Strategic tariff Equilibria", Journal of International Economics, 14, 145-61.

Venables, A. J. (1990), "International capacity choice and national market games", Journal of International Economics, 29, 23-42.

Venables, A. J. (1994), "Tariffs and Subsidies with Price Competition and Integrated Markets; The Mixed Strategy Equilibria”, Oxford Economic Papers, 46, 30-44. 